\title{
Prenatal exposure of ethanol induces increased glutamatergic neuronal differentiation of neural progenitor cells
}

\author{
Ki Chan Kim ${ }^{1 \dagger}$, Hyo Sang Go ${ }^{1 \dagger}$, Hae Rang Bak , Chang Soon Choi², Inha Choi ${ }^{2}$, Pitna Kim², Seol-Heui Han², \\ So Min Han', Chan Young Shin², Kwang Ho Ko ${ }^{1 *}$
}

\begin{abstract}
Background: Prenatal ethanol exposure during pregnancy induces a spectrum of mental and physical disorders called fetal alcohol spectrum disorder (FASD). The central nervous system is the main organ influenced by FASD, and neurological symptoms include mental retardation, learning abnormalities, hyperactivity and seizure susceptibility in childhood along with the microcephaly. In this study, we examined whether ethanol exposure adversely affects the proliferation of NPC and de-regulates the normal ratio between glutamatergic and GABAergic neuronal differentiation using primary neural progenitor culture (NPC) and in vivo FASD models.
\end{abstract}

Methods: Neural progenitor cells were cultured from E14 embryo brain of Sprague-Dawley rat. Pregnant mice and rats were treated with ethanol (2 or $4 \mathrm{~g} / \mathrm{kg} /$ day) diluted with normal saline from E7 to E16 for in vivo FASD animal models. Expression level of proteins was investigated by western blot analysis and immunocytochemical assays. MTT was used for cell viability. Proliferative activity of NPCs was identified by BrdU incorporation, immunocytochemistry and FACS analysis.

Results: Reduced proliferation of NPCs by ethanol was demonstrated using BrdU incorporation, immunocytochemistry and FACS analysis. In addition, ethanol induced the imbalance between glutamatergic and GABAergic neuronal differentiation via transient increase in the expression of Pax6, Ngn2 and NeuroD with concomitant decrease in the expression of Mash1. Similar pattern of expression of those transcription factors was observed using an in vivo model of FASD as well as the increased expression of PSD-95 and decreased expression of GAD67.

Conclusions: These results suggest that ethanol induces hyper-differentiation of glutamatergic neuron through Pax6 pathway, which may underlie the hyper-excitability phenotype such as hyperactivity or seizure susceptibility in FASD patients.

\section{Background}

Fetal alcohol spectrum disorder (FASD) is a spectrum of mental and physical disorders associated with prenatal exposure to alcohol during pregnancy, which affects one in every 100 live births in United states and Europe [1]. Ethanol has well-known teratogenic effects by mechanisms including induction of apoptosis and inhibition of proliferation, migration, differentiation, and other

\footnotetext{
*Correspondence: khk123@snu.ac.kr

+ Contributed equally

'Department of Pharmacology, College of Pharmacy, Seoul National

University, Seoul, Korea

Full list of author information is available at the end of the article
}

cellular functions during developmental period [2-5]. In addition, ethanol exposure influences membraneassociated receptor signaling pathways [6], cell adhesion $[7,8]$, and the binding of transcription factors [9].

The central nervous system is the main organ affected by FAS [10-13], and neurological symptoms include mental retardation, learning disabilities and ADHD-like symptoms such as hyperactivity in childhood $[14,15]$. Children with FASD usually exhibit smaller brain size, so-called microcephaly [16]. Recent studies suggest that alcohol interferes with the migration and organization of

\section{Biomed Central}


brain cells which may cause structural deformities or deficits within the brain.

Neural stem/progenitor cells (NPCs) are selfrenewable cells in the CNS. NPC is able to differentiate into specific cell types including neuron during the brain developmental period by its multi-potent capacity. Disorder of neural development might be induced by the de-regulation of NPC proliferation and differentiation, which may cause bigger influence in the entire architecture of the brain compared with the neurotoxic effects of risk factors in later period of life. This is especially true considering the fact that neuron is amitotic after differentiation [17], although there are a few known exceptions [18]. Therefore it is reasonable idea that prenatal ethanol affects overall architecture and size of the brain by influencing the proliferation and differentiation properties of NPCs during developmental periods. Regarding the effect of ethanol on NPCs, it inhibits the proliferation of adult hematopoietic stem cells as well as NPCs $[19,20]$ and suppresses neurogenesis $[21,22]$ in adolescent and adult brain. However, relatively few things are known regarding the effect of ethanol consumption during gestational periods on NPC proliferation and differentiation.

In addition to the regulation of proliferation of NPCs, balance between excitatory and inhibitory neurons in the brain plays a very important role in neurological function of brain. For example, imbalance between excitatory and inhibitory synapses is related to autistic symptoms [23]. This imbalance of excitation and inhibition could be due to the increased excitatory signaling, or to a reduction in inhibition due to a reduction in inhibitory signaling [24]. Increasing the numerical or functional balance of excitatory vs. inhibitory cells can lead to a hyper-excitable state, which might be an underlying neurobiological feature in the manifestation of neurological abnormalities such as hyperactivity symptoms of FASD.

Excitatory neuronal differentiation from NPC is activated by expression of specific transcription factors which act as proneural genes. Proneural genes are both necessary and sufficient to initiate the development of neuronal lineages and to promote the generation of progenitor cells that have a capacity to differentiate. Importantly, proneural genes have been shown to have information into the neurogenesis [25] and to contribute to the control of progenitor-cell identity [26]. Current studies focus on understanding the mechanisms of the multiple functions of proneural genes in neural development [27]. For example, Pax6, a proneural gene originally implicated in eye development, has been suggested in the regulation of glutamatergic neuronal fate. Pax6 induces expression of Ngn2 and NeuroD, which are involved in glutamatergic differentiation and reduces expression of Mash1, which induces GABAergic differentiation.

In this study, we examined the effect of prenatal ethanol consumption on proliferation of NPCs along with the regulation of excitatory and inhibitory neuronal differentiation.

\section{Methods}

\section{Materials}

Hanks balanced salt solution (HBSS), Dulbecco's Modified Eagle's medium/F12 (DMEM/F12), fetal bovine serum (FBS), penicillin/Streptomycin, and $0.25 \%$ Trypsin-EDTA were purchased from GibcoBRL (Grand Island, NY). poly-l-ornithine, Tween 20 were purchased from Sigma (St. Louis, MO). ECL ${ }^{\mathrm{mi}}$ Western blotting detection reagents were obtained from Amersham Life Science (Arlington Heights, IL). B-27 supplement were purchased from Invitrogen (Carlsbad, CA).

Antibodies were purchased from the following companies: anti- $\beta$-actin from Sigma (St. Louis, MO), phospho histone $\mathrm{H} 3$ antibody from Upstate Biologicals (Lake Placid, NY), neuronal class III $\beta$ - tubulin (Tuj-1) antibody from Covance (Richmond, CA), antibodies against nestin, synaptophysin, neuN, Pax6, Neurogenin2 (ngn2) and GAD67 from Millipore (Temecula, CA) and antibodies against Mash1/Achaete-scute homolog 1(Mash1), PSD95, NeuroD1, vGluT1, PCNA and BrdU were obtained from Abcam (Cambrigeshire, England).

\section{Culture of primary neural stem cells}

Neural progenitor cell culture was prepared form E14 embryo SD rat according to previously published procedure $[28,29]$, which was slightly modified by us [30]. In brief, cortices were dissociated into single cells by pipetting several times and passed through $40 \mu \mathrm{m}$ cell strainer (BD falcon, BD science, Franklin Lakes, NJ). Dissociated single cells were incubated with Dulbecco's modified Eagle's medium/F12 (DMEM/F12) containing B-27 supplement with $20 \mathrm{ng} / \mathrm{ml}$ EGF (Upstate) and 10 $\mathrm{ng} / \mathrm{ml}$ FGF (Invitrogen) at $37^{\circ} \mathrm{C}$ for 4 days in $5 \% \mathrm{CO}_{2}$ incubator. The cells grew into floating neurosphere were dissociated with trypsin-EDTA (GibcoBRL) and then resulting single cells were counted and plated on poly-lornithine (Sigma) coated plate with DMEM/F12 media containing B-27 supplement for further experiments.

\section{In vivo ethanol treatment}

Pregnant mice and rats were obtained from Daehan Bio Link (Daejeon, Korea) at gestation day (E2) and stabilized under environmental controlled rearing system maintained $12 \mathrm{hr}$ light-dark cycle for 4 days. The animals were treated with ethanol (Hayman, UK; 2 or $4 \mathrm{~g} / \mathrm{kg} /$ day; $25 \mathrm{v} / \mathrm{v} \%$ ) diluted with normal saline from E7 to E16 via intragastric intubation. Control groups 
were treated with normal saline. The daily dose was delivered in two halves each in the morning and evening to minimize the deleterious effects of binge alcohol drinking. At E12, P3 and 6 weeks after birth, brain was removed from the offsprings and analyzed for target protein expression by Western blot or immunohistochemistry. All animal experiments were conducted in accordance with the approved procedure either by the Konkuk University or Seoul National University Animal Care and Experimentation Committee.

\section{Western blot analysis}

Cells were washed twice with PBS and lysed with $2 \times$ SDS-PAGE sample buffer. An aliquot containing $50 \mu \mathrm{g}$ of total protein was separated by $10 \%$ SDS-PAGE and transferred to nitrocellulose membranes. The membranes were blocked with $1 \%$ polyvinylalcohol in PBS containing $0.2 \%$ tween- 20 for $10 \mathrm{~min}$. The membranes were incubated at $4^{\circ} \mathrm{C}$ for overnight with first antibodies directed against target proteins such as nestin, tuj-1, pax6, ngn2, neuroD, mash1, PSD95, GAD67(all 1:5000), which were diluted in blocking buffer ( $5 \%$ or $1 \%$ skim milk in PBS-Tween (0.2\% tween-20)). Membranes were washed 3 times with PBS-Tween for $10 \mathrm{~min}$, and then incubated with species specific peroxidase-conjugated secondary antibodies (Santa Cruz, CA), which were diluted in blocking buffer (5\% skim milk in PBS-Tween) for $2 \mathrm{hrs}$ at room temperature. Specific bands were detected using the ECL system (Amersham) and exposed to Bio-Rad electrophoresis image analyzer (BioRad, Hemel Hampstead, UK).

\section{MTT assay}

To determine the viability of cell, we used MTT assay. NPCs were incubated for $60 \mathrm{~min}$ with $500 \mu \mathrm{g} / \mathrm{ml}$ MTT reagent (3-(4, 5-dimethylthiazol-2-yl)-2,5-diphenyltetrazlium bromide, a tetrazole, Sigma) in the dark. After incubation, medium was removed and the formazan dye was extracted using $100 \%$ ethanol. The absorbance was determined using a microplate reader (Spectrafluor, Tecan Trading AG, Austria) at $590 \mathrm{~nm}$.

\section{BrdU (5-bromo-2-deoxyuridine, Bromodeoxyuridine) incorporation}

Proliferation of NPCs was measured using BrdU ELISA kit (Roche, Mannheim, Germany) following manufacturer's instruction. After ethanol treatment, cells grown in 96 -well plate were incubated at $37^{\circ} \mathrm{C}$ for 24 hrs with $10 \mu \mathrm{M}$ of BrdU labeling solution. After removing BrdU labeling solution, cells were fixed for $30 \mathrm{~min}$ at room temperature. Fixative was washed away and $100 \mu \mathrm{l}$ of anti-BrdU solution was added for 2 hrs. After washing with PBS for three times, colors were developed using anti-BrdU-POD solution and were incubated for 10-30 min at room temperature. We added $1 \mathrm{~N} \mathrm{HCl}(50 \mu \mathrm{l} /$ well $)$ until the absorbance was sufficient for photometric detection and then the absorbance was measured using an ELISA reader (Spectrafluor) at $450 \mathrm{~nm}$.

\section{Fluorescent Activated Cell Sorting Analysis (FACS)}

Cell cycle of NPCs was analyzed by FACS analysis. Plated single cells were trypsinized with trypsin-EDTA and were suspended in PBS with 1\% FBS. Suspension was centrifuged at $3000 \mathrm{rpm}$ for $3 \mathrm{~min}$ and supernatant was removed as completely as possible without disturbing the pellet. Suspended cell was fixed with $70 \%$ ethanol in PBS and was incubated for overnight at $4^{\circ} \mathrm{C}$. Supernatants were removed after centrifugation as above and cells were incubated with $50 \mu \mathrm{g} / \mathrm{ml}$ propidium iodide (Sigma) and $100 \mu \mathrm{g} / \mathrm{ml}$ ribonuclease A (Sigma) in $500 \mu \mathrm{l}$ PBS with $1 \%$ FBS. Samples were kept at room temperature, protected from the light for 30-40 min prior to analysis. Cell cycle of NPCs was analyzed using an FACS cytometer (BD bioscience).

\section{Immunocytochemistry}

Cultured NPCs or differentiated cells on cover glass (Fisher Scientific, PA) were washed and fixed with $4 \%$ paraformaldehyde at $4^{\circ} \mathrm{C}$ for $2 \mathrm{hrs}$. The cells were treated with $0.3 \%$ Triton $\mathrm{X}-100$ for $15 \mathrm{~min}$ at room temperature and were blocked for $30 \mathrm{~min}$ with blocking buffer (1\% BSA, 5\% FBS in PBS) at room temperature. The cells were incubated for overnight at $4^{\circ} \mathrm{C}$ with primary antibodies against phospho-histone $\mathrm{H} 3$ (rabbit, 1:500), tuj-1 (rabbit, 1:500), nestin (mouse, 1:500), GAD67 (mouse, 1:500), and neuroD (rabbit, 1:500) diluted in blocking buffer, and were washed with washing buffer $(0.1 \%$ BSA, $0.5 \%$ FBS in PBS) for 3 times. Secondary antibodies conjugated with TMRE (antimouse, 1:100) or FITC (anti-rabbit, 1:100 were diluted in blocking buffer and incubated for 2 hrs at room temperature in the dark condition.), In some cases, nucleus was co-stained with DAPI (4'-6-diamidino-2-phenylindole) staining solution (1:100, Invitrogen). After washed 3 times with washing buffer, the cover glass were mounted in Vectashield (Vector laboratories, Burlingame, CA) and viewed with a confocal microscope (TCS-SP, Leica, Heidelberg, Germany).

\section{Statistical analysis}

Data were expressed as the mean \pm standard error of mean (S.E.M) and analyzed for statistical significance using one way analysis of variance (ANOVA) followed by Newman-Keuls test as a post hoc test and a P value $<0.05$ was considered significant. 


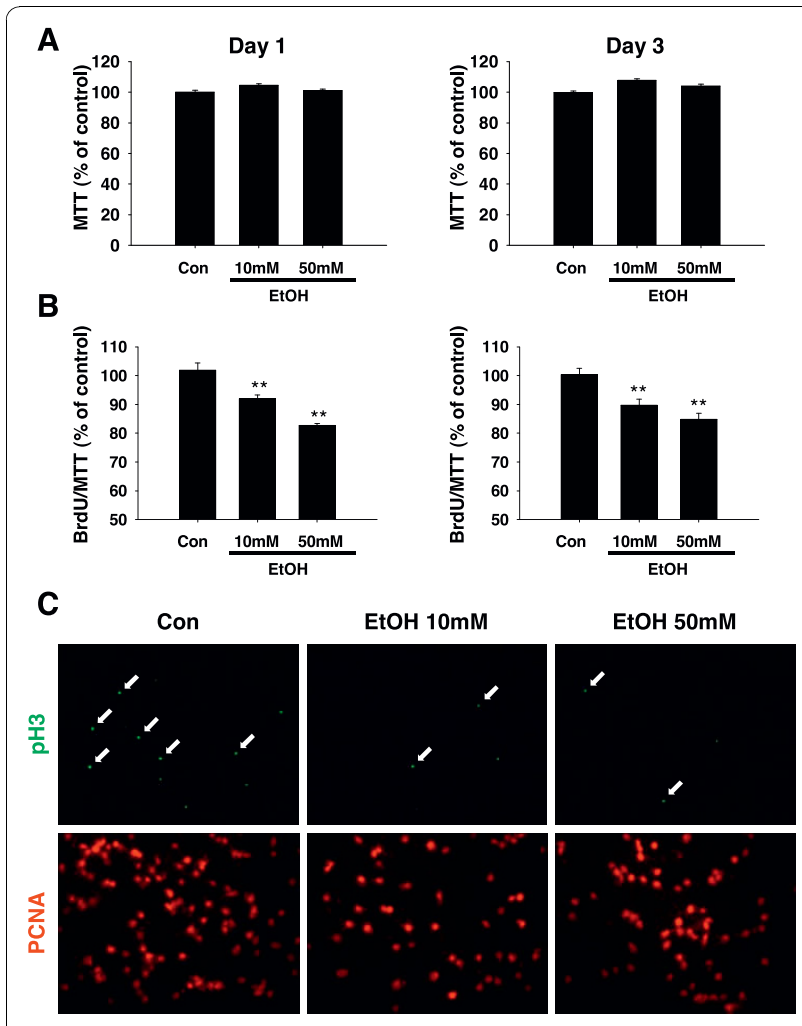

D

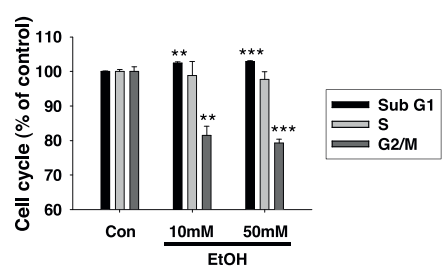

Figure 1 Ethanol inhibited the proliferation of NPCs. We treated two concentrations ( $10 \mathrm{mM}$ and $50 \mathrm{mM}$ ) of ethanol to rat primary NPCs culture for 1 or 3 days. Cell viability (A) and BrdU

incorporation (B) was examined as described in methods. (A) MTT analysis. Ethanol did not induce cellular toxicity against NPCs. (B) Both on day 1 and 3, BrdU incorporation was inhibited by ethanol treatment in a concentration-dependent manner. (C) To investigate inhibitory effect of ethanol on cell proliferation,

immunocytochemistry against $\mathrm{pH} 3$ or PCNA was performed on day 3. The number of pH3-positive cells as well as PCNA positive cells was reduced by ethanol treatment. (D) FACS analysis of cell cycle. FACS analysis was performed as described in methods $4 \mathrm{hr}$ after ethanol treatment on NPCs culture. Ethanol treatment decreased cells in G2/M phase as compared with control. Values are expressed as the mean \pm S.E.M. ${ }^{* *}$, ${ }^{* *} p<0.01$ and $<0.001$ vs. control ( $n=5$ for $A, B$ and $C . n=3$ for $D)$.

\section{Results}

\section{Ethanol inhibited proliferation of neural stem cell}

We first determined the effect of ethanol on NPCs viability. Ethanol did not show toxicity to NPCs culture, which was determined by MTT assay at all concentration and duration we used in this study (Figure 1A).
To determine anti-proliferative effect of ethanol, BrdU incorporation assay was performed. BrdU is a synthetic nucleoside that is an analogue of thymidine, which is commonly used for the detection of proliferating cell. The BrdU assay measures cells that have synthesized DNA within a given time period. The percentage of BrdU-positive cells was reduced compared with control after treatment with 10 and $50 \mathrm{mM}$ ethanol (Figure 1B). The inhibition of BrdU incorporation by ethanol showed concentration dependency and the extent of inhibition was higher when the cells were treated with ethanol for 3 days.

To further investigate the anti-proliferative effect of ethanol, cells were immunostained for phospho-histone $\mathrm{H} 3(\mathrm{pH} 3)$ and Proliferating Cell Nuclear Antigen (PCNA), as markers for dividing cells. The number of $\mathrm{pH} 3$ or PCNA-positive cell was significantly reduced by ethanol treatment in a concentration dependent manner (Figure 1C) suggesting that ethanol inhibits the cell cycle progression of NPCs culture.

To determined mechanism of anti-proliferative effect of ethanol, we performed FACS analysis. Quantitative graph represented relative proportion of sub G1, S and G2/M phases in control and 10 or $50 \mathrm{mM}$ ethanol treated groups. In quantitative analysis of FACS data, ethanol treatment to NPCs culture slightly increased cells in sub G1 phase and decreased the proportion of cells in G2/M phase as compared with control (Figure 1D) suggesting the inhibitory role of ethanol during G2/M cell cycle progression of NPCs culture.

\section{Ethanol increased neurogenesis}

We next examined the differentiation of NPCs by Western blot analysis and immunocytochemistry assays using cell specific marker proteins. Nestin was used as an undifferentiated neural stem cell marker, and Tuj-1 was used for neuron. In western blot analysis, the level of nestin was decreased on day 3 after ethanol treatment (Figure 2A), which is consistent with the inhibitory effect of ethanol on NPCs proliferation as described in Figure 1 . On the contrary, the level of Tuj-1 was significantly increased about 2-fold compared to control with $50 \mathrm{mM}$ of ethanol treatment (Figure 2B). These results suggest that ethanol induced neural stem cell differentiation into neuron while inhibiting the proliferation of NPCs in the early stage of neurogenesis. In immunochemical staining, the number of nestin positive cells was decreased by ethanol treatment while Tuj-1 positive cells showed increased number and length of neural processes with stronger immunoreactivity (Figure 2C). The differences in neural differentiation by ethanol were disappeared if we extended the differentiation period to 7 days suggesting that ethanol may promote the kinetics of neural differentiation but not the neural fate (neuron 

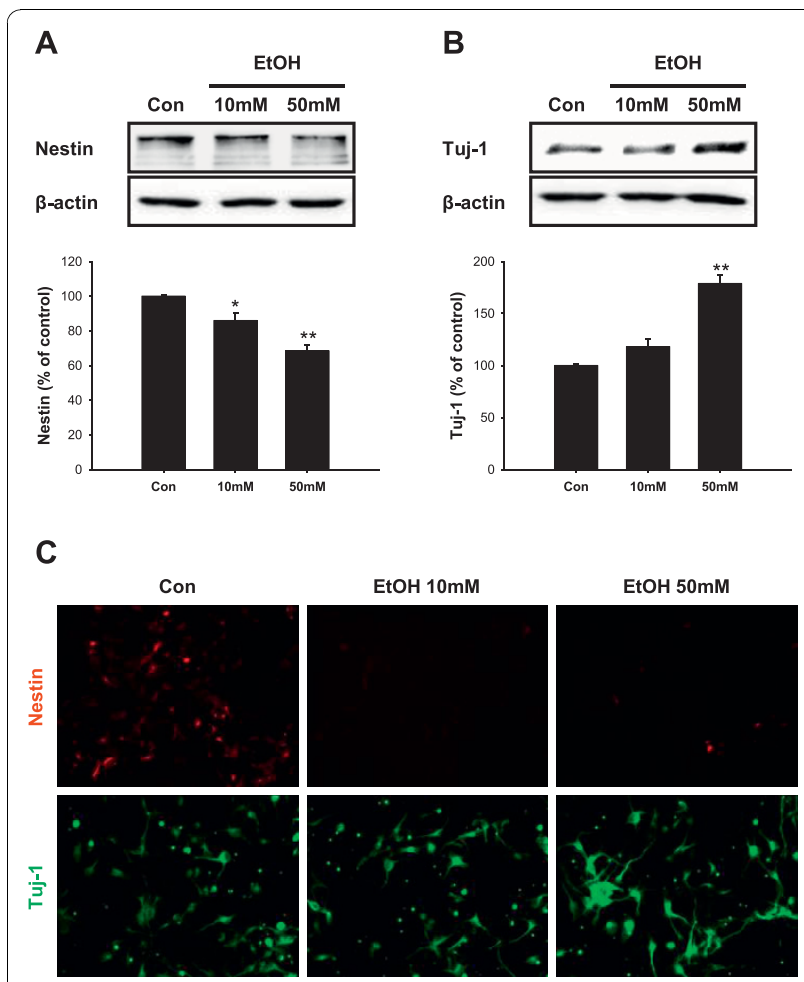

Figure 2 Ethanol induced early neurogenesis from NPCs. (A) Expression of Nestin and (B) Tuj-1 was determined by Western blot after ethanol treatment. Ethanol $(50 \mathrm{mM})$ decreased the expression of Nestin to $70 \%$ of control level and increased that of Tuj- 1 to $170 \%$ of control value. (C) Immunocytochemical staining of nestin and Tuj-1. Similar results were obtained as Western blot. Values are expressed as the mean \pm S.E.M. ${ }^{*}$, ${ }^{*} p<0.05$ and $<0.01$ vs. control $(n=5)$.

vs. glia) determination itself (data not shown) in our experimental condition.

\section{Glutamatergic neuronal differentiation was induced by ethanol through Pax6 expression}

To investigate whether ethanol alters the balance of excitatory/inhibitory neuronal differentiation, we first examined the level of expression of proneural genes after ethanol treatment. Proneural genes such as Pax6, Ngn2 and NeuroD are expressed in stepwise pattern during developmental periods and have been suggested to promote excitatory neuronal differentiation. Expression of Pax6, Ngn2 and NeuroD was increased 1 day after ethanol treatment compared to control (Figure 3A). However, the level of Mash1, which have been implicated in inhibitory neuronal differentiation, was decreased in the same condition (Figure 3A). These data suggest that the number of excitatory neuron might be higher than that of inhibitory neuron and we performed Western blot analysis using the marker protein, PSD95 as a glutamatergic neuronal

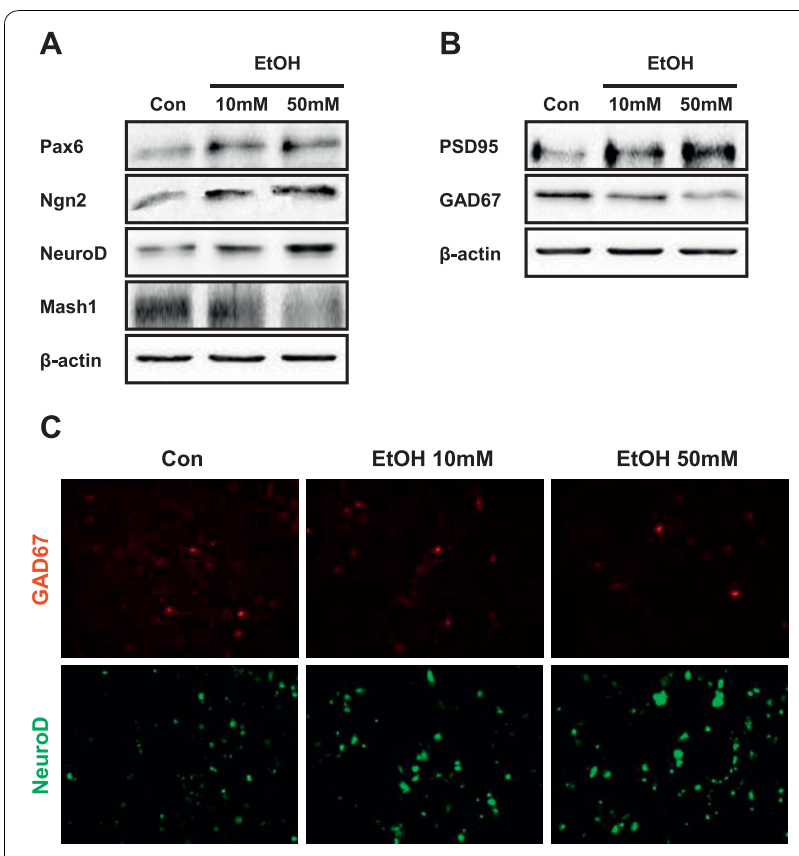

D
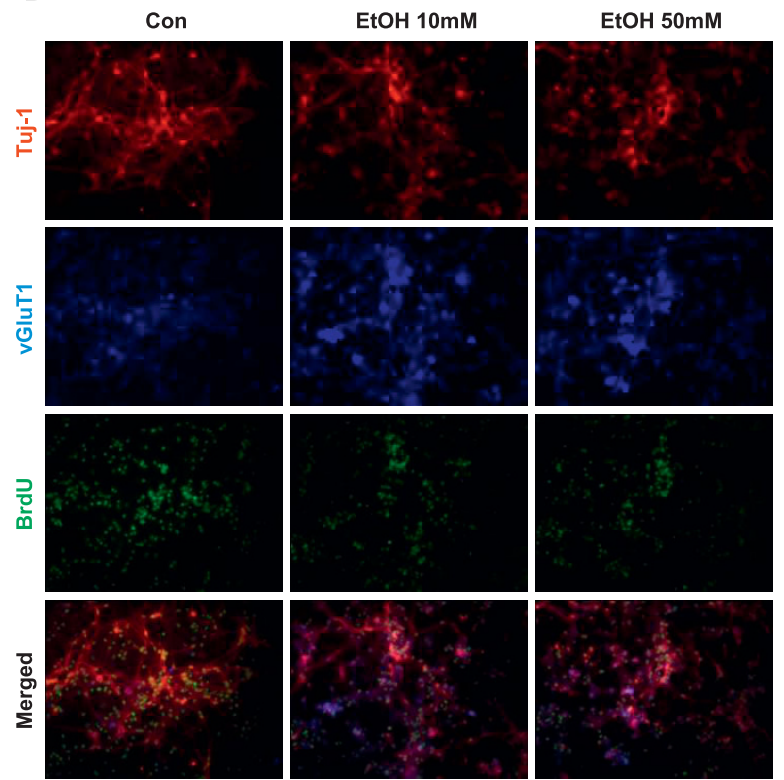

Figure 3 Increased expression of Pax 6 and glutamatergic neuronal differentiation by ethanol treatment. NPCs were treated with ethanol and Western blot and immunocytochemistry were performed to determine the expression of Pax6 and downstream transcription factors (A) as well as glutamatergic and GABAergic neuronal subtype markers (B). (C) Immunocytochemical staining of GABAergic marker GAD67 and a regulator of excitatory neuronal differentiation, NeuroD, in NPCs treated with ethanol. (D) Triple immunocytochemical staining of neuronal marker Tuj1 (red) and vGluT1 (blue), a marker for glutamatergic neuron along with BrdU (green) staining, a marker for proliferated cells. Most of the vGluT1-positive cells were co-localized with BrdU staining. 
marker and GAD67 as an inhibitory neuronal marker. The level of PSD95 was significantly increased in neurons differentiated for 7 days from NPCs by single ethanol treatment. On the contrary, the level of GAD67 was decreased in the same condition (Figure 3B). Immunocytochemistry also showed increased expression of NeuroD and decreased expression of GAD67 by ethanol treatment (Figure 3C). Immunocytochemical reactivity for vGluT1, a marker for glutamatergic neuron, also increased by ethanol treatment (Figure 3D). Positive cells against vGluT1 were also positive against BrdU staining, suggesting that neural progenitor cells are differentiated into glutamatergic neuron. Altogether, these results suggest that exposure to ethanol induced early neurogenesis while inhibiting proliferation of NPCs, and modified the balance of glutamatergic/GABAergic neuronal differentiation.

\section{Increased expression of Pax6 and glutamatergic neuronal} differentiation by prenatal ethanol exposure in vivo

Next, we examined the effect of ethanol on neural stem cell differentiation in FASD animal models. Pregnant mice were administered with ethanol $(2 \mathrm{~g} / \mathrm{kg}$ and $4 \mathrm{~g} / \mathrm{kg}$ ) on E6 until E16 and we investigated the expression of Pax6, Ngn2 and NeuroD by Western blot. The level of these transcription factors was significantly

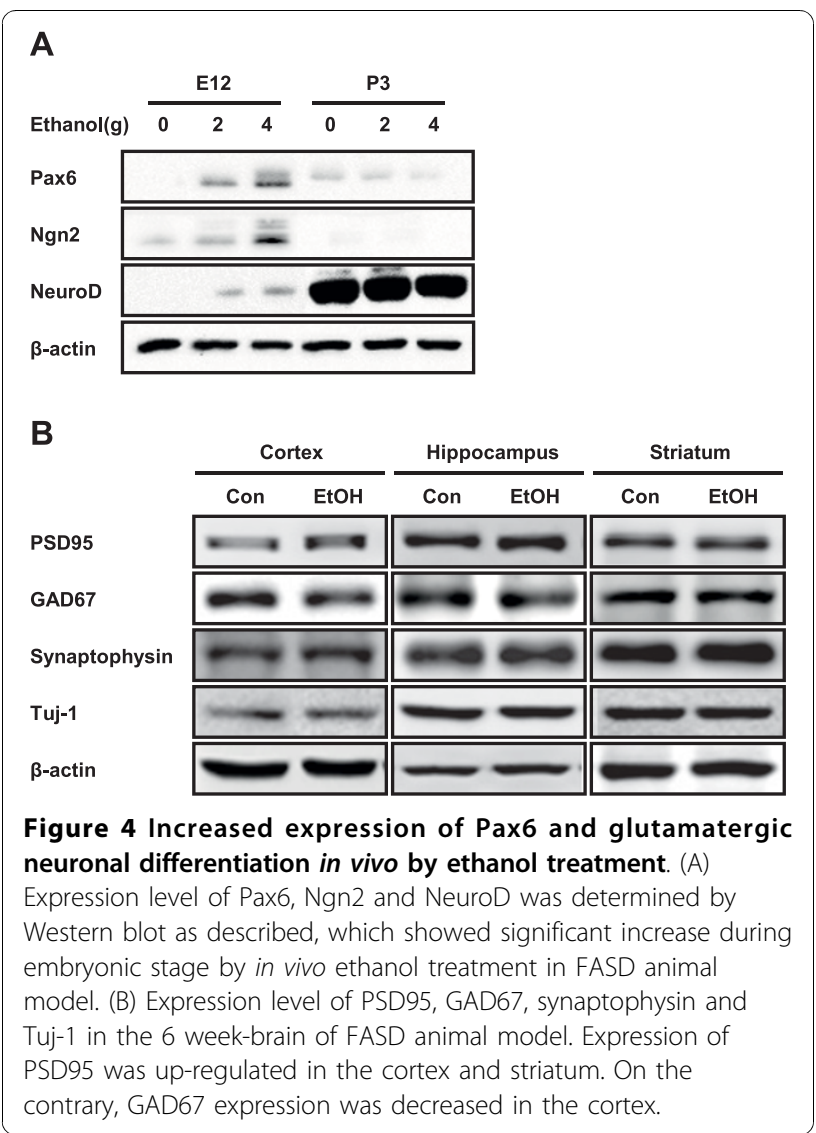

increased in the brain of E12 embryonic mice from dams ingested ethanol (Figure 4A). At postnatal day 3, expression level of Pax6 and Ngn2 was decreased both in control and ethanol groups almost below the detection limit and the level of NeuroD, which modulates neuronal maturation, was significantly increased in postnatal period although there is not much difference between treatment groups (Figure 4A). We next examined the expression level of PSD95, GAD67, synaptophysin and Tuj-1 in the several brain regions of FASD rat animal models at 6 weeks, the time point that the neural developments are already completed. Compared to the control group, the level of PSD95 was significantly increased in cortex and to a lesser extent in hippocampus, but not in striatum. Likewise, we observed a slight increase in the expression level of synaptophysin in cortex and hippocampus of prenatally ethanol exposed rats. On the other hand, the level of GAD67 was reduced in the cortex and hippocampus of prenatally ethanol-treated group. The level of Tuj-1 and $\beta$ actin determined by Western blot (Figure 4B) as well as NeuN and Tuj-1 immunohistochemical staining (data not shown) did not show significant difference in all brain regions examined, which suggest that the total number of neuron is not different between control and prenatally ethanol-exposed groups. Altogether, these results suggest that prenatal ethanol exposure induced glutamatergic neuronal differentiation through increased expression of Pax6, Ngn2 and NeuroD in both in vitro and in vivo conditions.

\section{Discussion}

Excess alcohol consumption during pregnancy exerts teratogenic effects on the fetus, including abnormalities of the central nervous system, general growth retardation and craniofacial defects, which are collectively called FASD [31-35]. Recently, it becomes clear that prenatal exposure to ethanol may induce alterations in neurobehavioral phenotypes or performance of executive functions in the offsprings without obvious physical deformation such as facial changes. It is self-evident that the neuropathological changes may involve either or both the alterations in neural stem cell proliferation and differentiation, and a few studies investigated the effects of prenatal alcohol exposure on the NPCs proliferation and neuronal development. Previous studies have suggested that prenatal ethanol exposure may affect CNS development, which range from the apoptotic death of stem cell population to modulation of cell cycle progress during neurulation or neurogenesis periods [33,36-38]. More recently, it has been suggested that alcohol may affect the differentiation of cortical neurons in vitro [37] as well as hippocampal neurons in vivo [39]. In addition, alterations in astroglial differentiation have also been 
suggested $[40,41]$. Here, we demonstrated that ethanol inhibited proliferation of NPCs and induced early differentiation of neuron. It also modulated excitatory/inhibitory neuronal differentiation both in vitro and in vivo, which might be related to the hyper-excitability of prenatally ethanol-exposed subjects.

Although increased apoptosis [42], interruption to cell proliferation [43], and impaired protein and DNA synthesis [44] have been reported as a possible mechanism underlying the teratogenic effect of ethanol, mechanisms regulating the neurological symptoms of FASD have not been clearly explained yet. Suggested mechanisms includes DNA methylation $[45,46]$, modulation of phospholipase D signaling [47], apoptosis [48-50], and alteration in neuronal migration [51] as well as changes in neurotransmitter systems [52].

Excitatory neuronal differentiation from NPCs is activated by expression of specific transcription factors. Past studies emphasized the role of Pax6 in eye development $[53,54]$. Recently, another role of Pax6 as a neuronal subtype determinant is magnified. Pax6 is expressed at NPCs committed to glutamatergic neuronal fate [55]. Pax6 induces the expression of Ngn2 and NeuroD, which again involved in glutamatergic differentiation, while reduces the expression of Mash1, an enhancer of GABAergic differentiation [56-60].

However, it should be remembered that the expression of Pax6 is also associated with the regulation of stem cell proliferation and brain microcephaly. In the neocortex, functional loss of Pax6 results in microcephaly which might be induced by an abnormal development of the secondary progenitor population of the subventricular zone (SVZ), also known as basal progenitor cells (BP cells) [61-64]. In a study using Xenopus embryo, Peng et al reported that exposure to ethanol reduced the expression of several regulators of development including Xenopus Pax6 (xPAX6) more than 90\%, which might be related to the microcephaly [65]. More recently, similar findings were reported with pregnant Wistar rats and their offsprings [66]. Obviously, these results are inconsistent with our results, which showed increase in Pax6 level by ethanol treatment both in vivo and in vitro. The most important difference of the previous experiments and ours might be the difference in the route of ethanol treatment. In the study of Aronne et al., they treated pregnant Wistar rats with ethanol by intraperitoneal injection $(3.5 \mathrm{~g} / \mathrm{kg})$ from gestational day 10 to 18 (G10-G18). Interestingly, they found that fetal weights and cerebral cortex thickness were significantly lower in G18 prenatally ethanol exposed rat fetuses than in control fetuses as well as neural tube defects. In our study, we used gastric intubation protocol to mimic actual binge drinking situation and did not found defects in weight gain and any other physical malformations suggesting that our protocol is much milder compared to that of other researchers, although it is also possible that species difference may account for the different results. Whether there is biphasic bell shaped concentration response curve for the expression level of Pax6 and the resulting neurodevelopmental consequences, would be a intriguing and must be answered question to further extend our understanding about the effect of parental alcohol consumption on the neurobiological phenotype in offsprings.

In the present study, prenatal ethanol promoted excitatory neuronal differentiation, possibly via increased expression of Pax6, Ngn2 and NeuroD. Increasing the numerical ratio of excitatory/inhibitory cells can lead to a hyper-excitable state, which might be related to the hyperactivity symptoms observed in FASD patients. In fact, defects in either the production or migration of cortical GABAergic neurons can lead to decreased numbers of cortical GABAergic neurons, which result in a hyper-excitable cortex [67]. Mutations in GAD65, which may also induce the reduction of inhibition in the mouse cerebral cortex, interfere in the maturation of binocular vision [68]. After perinatal early exposure to ethanol, the expression of $\mathrm{GABA}_{\mathrm{A}}$ receptor or GABA synaptic proteins as well as GABAergic synaptic transmission has been reported to be impaired $[52,69,70]$. Fetal exposure to alcohol is also related to a higher susceptibility to convulsions. Recently, it has been suggested that genetically epilepsy prone rats (GEPRs) display susceptibility to audiogenic seizure after fetal exposure to ethanol while there is general reduction in susceptibility against pentylenetetrazole-induced seizure compared to cognate control [71].

Although the mechanism for molecular signaling pathway directly modulating the ratio of excitatory/inhibitory neuron is unclear yet, the results from the present study may suggest that ethanol modulates the expression of key transcriptional factors involved in the excitatory neuronal differentiation. Whether the modulation of Pax6, Ngn2 and NeuroD by prenatal ethanol treatment is causally related to the regulation of excitatory neuronal differentiation and to hyperactive neuronal phenotype should be investigated further in the future study.

\section{Conclusions}

In this study, we demonstrated that ethanol exposure suppressed the proliferation of NPCs and affected excitatory/inhibitory neuronal subtype differentiation. Decreased proliferation of NPCs by ethanol was identified using BrdU incorporation, $\mathrm{pH} 3$ immunostaining and FACS analysis. Ethanol induced glutamatergic neuronal differentiation, possibly via transient increase in the expression of Pax6, Ngn2 and NeuroD with concomitant decrease in the expression of Mash1. Similar 
pattern of expression of above transcriptional factors as well as glutamatergic neuronal differentiation was shown using in vivo model. These results suggest that ethanol-induced hyper-differentiation of glutamatergic neuron via Pax6 pathway may underlie the hyper-excitability phenotype such as hyperactivity or seizure susceptibility in FASD, which may provide additional insights into the understanding of neurological aspects of FASD and devising pharmacological and molecular biological methods leading to the better treatment options.

\section{Acknowledgements}

This research was supported by Basic Science Research Program through the National Research Foundation of Korea (NRF) funded by the Ministry of Education, Science and Technology (2010-0016738).

\section{Author details}

'Department of Pharmacology, College of Pharmacy, Seoul National University, Seoul, Korea. ${ }^{2}$ School of Medicine and Center for Neuroscience Research, IBST, Konkuk University, Korea.

\section{Authors' contributions}

KCK participated in study design and conceptualization, analyzed data, and wrote the manuscript. HSG participated in data collection, analysis and study design. HRB performed experiment and helped with composing manuscript. CSC, IC and PK performed experiment for in vivo model. S-HH participated in study design. SMH helped with experiment. CYS conceptualized and designed the study. KHK contributed study design and revised the manuscript for intellectual content. All authors read and approved the final manuscript.

\section{Competing interests}

The authors declare that they have no competing interests.

Received: 3 August 2010 Accepted: 12 November 2010 Published: 12 November 2010

\section{References}

1. Sampson PD, Streissguth AP, Bookstein FL, Little RE, Clarren SK, Dehaene P, Hanson JW, Graham JM Jr: Incidence of fetal alcohol syndrome and prevalence of alcohol-related neurodevelopmental disorder. Teratology 1997, 56:317-326.

2. Gong Z, Wezeman FH: Inhibitory effect of alcohol on osteogenic differentiation in human bone marrow-derived mesenchymal stem cells. Alcohol Clin Exp Res 2004, 28:468-479.

3. Li Z, Lin H, Zhu Y, Wang M, Luo J: Disruption of cell cycle kinetics and cyclin-dependent kinase system by ethanol in cultured cerebellar granule progenitors. Brain Res Dev Brain Res 2001, 132:47-58.

4. Miller MW, Chiaia NL, Rhoades RW: Intracellular recording and injection study of corticospinal neurons in the rat somatosensory cortex: effect of prenatal exposure to ethanol. J Comp Neurol 1990, 297:91-105.

5. Siegenthaler JA, Miller MW: Transforming growth factor beta1 modulates cell migration in rat cortex: effects of ethanol. Cereb Cortex 2004, 14:791-802.

6. Resnicoff M, Sell C, Ambrose D, Baserga R, Rubin R: Ethanol inhibits the autophosphorylation of the insulin-like growth factor 1 (IGF-1) receptor and IGF-1-mediated proliferation of 3T3 cells. J Biol Chem 1993, 268:21777-21782.

7. Charness ME, Hu G, Edwards RH, Querimit LA: Ethanol increases deltaopioid receptor gene expression in neuronal cell lines. Mol Pharmacol 1993, 44:1119-1127.

8. Vangipuram SD, Grever WE, Parker GC, Lyman WD: Ethanol increases fetal human neurosphere size and alters adhesion molecule gene expression. Alcohol Clin Exp Res 2008, 32:339-347.
9. Pignataro L, Miller AN, Ma L, Midha S, Protiva P, Herrera DG, Harrison NL: Alcohol regulates gene expression in neurons via activation of heat shock factor 1. J Neurosci 2007, 27:12957-12966.

10. Jirikowic T, Kartin D, Olson HC: Children with fetal alcohol spectrum disorders: a descriptive profile of adaptive function. Can J Occup Ther 2008, 75:238-248.

11. Peadon E, Fremantle $E$, Bower C, Elliott EJ: International survey of diagnostic services for children with Fetal Alcohol Spectrum Disorders. BMC Pediatr 2008, 8:12.

12. Chudley AE, Conry J, Cook JL, Loock C, Rosales T, LeBlanc N: Fetal alcohol spectrum disorder: Canadian guidelines for diagnosis. CMAJ 2005, 172: S1-S21.

13. Quick S: Fetal alcohol syndrome: the nurse practitioner perspective. J Am Acad Nurse Pract 1996, 8:343-349, quiz 350-342.

14. Green JH: Fetal Alcohol Spectrum Disorders: understanding the effects of prenatal alcohol exposure and supporting students. I Sch Health 2007, 77:103-108.

15. Kodituwakku P, Coriale G, Fiorentino D, Aragon AS, Kalberg WO, Buckley D, Gossage JP, Ceccanti M, May PA: Neurobehavioral characteristics of children with fetal alcohol spectrum disorders in communities from Italy: Preliminary results. Alcohol Clin Exp Res 2006, 30:1551-1561.

16. Elliott EJ, Payne J, Morris A, Haan E, Bower C: Fetal alcohol syndrome: a prospective national surveillance study. Arch Dis Child 2008, 93:732-737.

17. Herrup K, Yang Y: Cell cycle regulation in the postmitotic neuron: oxymoron or new biology? Nat Rev Neurosci 2007, 8:368-378.

18. Alvarez-Buylla A, Garcia-Verdugo JM: Neurogenesis in adult subventricular zone. J Neurosci 2002, 22:629-634.

19. Rice AC, Bullock MR, Shelton KL: Chronic ethanol consumption transiently reduces adult neural progenitor cell proliferation. Brain Res 2004, 1011:94-98.

20. Prakash O, Rodriguez VE, Tang ZY, Zhou P, Coleman R, Dhillon G, Shellito JE, Nelson S: Inhibition of hematopoietic progenitor cell proliferation by ethanol in human immunodeficiency virus type 1 tatexpressing transgenic mice. Alcohol Clin Exp Res 2001, 25:450-456.

21. Crews FT, Mdzinarishvili A, Kim D, He J, Nixon K: Neurogenesis in adolescent brain is potently inhibited by ethanol. Neuroscience 2006, 137:437-445.

22. Nixon $\mathrm{K}$, Crews FT: Binge ethanol exposure decreases neurogenesis in adult rat hippocampus. J Neurochem 2002, 83:1087-1093.

23. Rubenstein $J$, Merzenich MM: Model of autism: increased ratio of excitation/inhibition in key neural systems. Genes Brain Behav 2003, 2:255-267.

24. Stief F, Zuschratter W, Hartmann K, Schmitz D, Draguhn A: Enhanced synaptic excitation-inhibition ratio in hippocampal interneurons of rats with temporal lobe epilepsy. Eur I Neurosci 2007, 25:519-528.

25. Klisch TJ, Souopgui J, Juergens K, Rust B, Pieler T, Henningfeld KA: Mxi1 is essential for neurogenesis in Xenopus and acts by bridging the panneural and proneural genes. Dev Biol 2006, 292:470-485.

26. Bertrand N, Castro DS, Guillemot F: Proneural genes and the specification of neural cell types. Nat Rev Neurosci 2002, 3:517-530.

27. Park CH, Kang JS, Kim JS, Chung S, Koh JY, Yoon EH, Jo AY, Chang MY, Koh $\mathrm{HC}$, Hwang $\mathrm{S}$, et al: Differential actions of the proneural genes encoding Mash1 and neurogenins in Nurr1-induced dopamine neuron differentiation. J Cell Sci 2006, 119:2310-2320.

28. Benoit BO, Savarese T, Joly M, Engstrom CM, Pang L, Reilly J, Recht LD, Ross AH, Quesenberry PJ: Neurotrophin channeling of neural progenitor cell differentiation. J Neurobiol 2001, 46:265-280.

29. Conti L, Pollard SM, Gorba T, Reitano E, Toselli M, Biella G, Sun Y, Sanzone S, Ying QL, Cattaneo E, Smith A: Niche-independent symmetrical selfrenewal of a mammalian tissue stem cell. PLOS Biol 2005, 3:e283.

30. Go HS, Shin CY, Lee SH, Jeon SJ, Kim KC, Choi CS, Ko KH: Increased proliferation and gliogenesis of cultured rat neural progenitor cells by lipopolysaccharide-stimulated astrocytes. Neuroimmunomodulation 2009, 16:365-376.

31. Autti-Ramo I, Fagerlund A, Ervalahti N, Loimu L, Korkman M, Hoyme HE: Fetal alcohol spectrum disorders in Finland: clinical delineation of 77 older children and adolescents. Am J Med Genet A 2006, 140:137-143.

32. Becker HC: The alcohol withdrawal "kindling" phenomenon: clinical and experimental findings. Alcohol Clin Exp Res 1996, 20:121A-124A.

33. Clarren SK, Smith DW: The fetal alcohol syndrome. Lamp 1978, 35:4-7. 
34. Jones KL, Smith DW: Recognition of the fetal alcohol syndrome in early infancy. Lancet 1973, 302:999-1001.

35. Olson HC, Streissguth AP, Sampson PD, Barr HM, Bookstein FL, Thiede K: Association of prenatal alcohol exposure with behavioral and learning problems in early adolescence. J Am Acad Child Adolesc Psychiatry 1997, 36:1187-1194.

36. Anthony B, Zhou FC, Ogawa T, Goodlett CR, Ruiz J: Alcohol exposure alters cell cycle and apoptotic events during early neurulation. Alcohol Alcohol 2008, 43:261-273.

37. Miranda RC, Santillano DR, Camarillo C, Dohrman D: Modeling the impact of alcohol on cortical development in a dish: strategies from mapping neural stem cell fate. Methods Mol Biol 2008, 447:151-168.

38. Ikonomidou C, Bittigau P, Ishimaru MJ, Wozniak DF, Koch C, Genz K, Price MT, Stefovska V, Horster F, Tenkova T, et al: Ethanol-induced apoptotic neurodegeneration and fetal alcohol syndrome. Science 2000, 287:1056-1060.

39. leraci A, Herrera DG: Single alcohol exposure in early life damages hippocampal stem/progenitor cells and reduces adult neurogenesis. Neurobiol Dis 2007, 26:597-605.

40. Rubert G, Minana R, Pascual M, Guerri C: Ethanol exposure during embryogenesis decreases the radial glial progenitorpool and affects the generation of neurons and astrocytes. J Neurosci Res 2006, 84:483-496.

41. Vemuri MC, Chetty CS: Alcohol impairs astrogliogenesis by stem cells in rodent neurospheres. Neurochem Int 2005, 47:129-135.

42. Goodlett CR, Horn KH, Zhou FC: Alcohol teratogenesis: mechanisms of damage and strategies for intervention. Exp Biol Med (Maywood) 2005, 230:394-406.

43. Rohan $T E$, Jain $M$, Miller AB: Alcohol consumption and risk of benign proliferative epithelial disorders of the breast: a case-cohort study. Public Health Nutr 1998, 1:139-145.

44. Shibley IA Jr, Pennington SN: Metabolic and mitotic changes associated with the fetal alcohol syndrome. Alcohol Alcohol 1997, 32:423-434.

45. Garro AJ, McBeth DL, Lima V, Lieber CS: Ethanol consumption inhibits fetal DNA methylation in mice: implications for the fetal alcohol syndrome. Alcohol Clin Exp Res 1991, 15:395-398.

46. Hicks SD, Middleton FA, Miller MW: Ethanol-Induced Methylation of Cell Cycle Genes in Neural Stem Cells. J Neurochem 2010.

47. Fujita Y, Hiroyama M, Sanbe A, Yamauchi J, Murase S, Tanoue A: ETOH inhibits embryonic neural stem/precursor cell proliferation via PLD signaling. Biochem Biophys Res Commun 2008, 370:169-173.

48. Hao HN, Parker GC, Zhao J, Barami K, Lyman WD: Differential responses of human neural and hematopoietic stem cells to ethanol exposure. $J$ Hematother Stem Cell Res 2003, 12:389-399.

49. Kentroti S, Vernadakis A: Survival and proliferation in developing neuroblasts in cultures derived from embryos treated with ethanol during early neuroembryogenesis: effects attenuated by somatostatin. $J$ Neurosci Res 1991, 30:641-648

50. Santillano DR, Kumar LS, Prock TL, Camarillo C, Tingling JD, Miranda RC: Ethanol induces cell-cycle activity and reduces stem cell diversity to alter both regenerative capacity and differentiation potential of cerebral cortical neuroepithelial precursors. BMC Neurosci 2005, 6:59.

51. Mooney SM, Siegenthaler JA, Miller MW: Ethanol induces heterotopias in organotypic cultures of rat cerebral cortex. Cereb Cortex 2004, 14:1071-1080.

52. Hsiao SH, DuBois DW, Miranda RC, Frye GD: Critically timed ethanol exposure reduces GABAAR function on septal neurons developing in vivo but not in vitro. Brain Res 2004, 1008:69-80.

53. Chanas SA, Collinson JM, Ramaesh T, Dora N, Kleinjan DA, Hill RE, West JD: Effects of elevated Pax6 expression and genetic background on mouse eye development. Invest Ophthalmol Vis Sci 2009, 50:4045-4059.

54. Favor J, Gloeckner CJ, Neuhauser-Klaus A, Pretsch W, Sandulache R, Saule S, Zaus I: Relationship of Pax6 activity levels to the extent of eye development in the mouse, Mus musculus. Genetics 2008, 179:1345-1355.

55. Kroll TT, O'Leary DD: Ventralized dorsal telencephalic progenitors in Pax6 mutant mice generate GABA interneurons of a lateral ganglionic eminence fate. Proc Natl Acad Sci USA 2005, 102:7374-7379.

56. Kageyama R, Ohtsuka T, Shimojo H, Imayoshi I: Dynamic Notch signaling in neural progenitor cells and a revised view of lateral inhibition. Nat Neurosci 2008, 11:1247-1251.

57. Guillemot F: Cellular and molecular control of neurogenesis in the mammalian telencephalon. Curr Opin Cell Biol 2005, 17:639-647.
58. Schuurmans C, Armant O, Nieto M, Stenman JM, Britz O, Klenin N, Brown C, Langevin LM, Seibt J, Tang H, et al: Sequential phases of cortical specification involve Neurogenin-dependent and -independent pathways. EMBO J 2004, 23:2892-2902.

59. Scardigli R, Baumer N, Gruss P, Guillemot F, Le Roux I: Direct and concentration-dependent regulation of the proneural gene Neurogenin2 by Pax6. Development 2003, 130:3269-3281.

60. Kawaguchi A, Ikawa T, Kasukawa T, Ueda HR, Kurimoto K, Saitou M, Matsuzaki F: Single-cell gene profiling defines differential progenitor subclasses in mammalian neurogenesis. Development 2008, 135:3113-3124.

61. Glaser T, Jepeal L, Edwards JG, Young SR, Favor J, Maas RL: PAX6 gene dosage effect in a family with congenital cataracts, aniridia, anophthalmia and central nervous system defects. Nat Genet 1994, 7:463-471.

62. Hill RE, Favor J, Hogan BL, Ton CC, Saunders GF, Hanson IM, Prosser J, Jordan T, Hastie ND, van Heyningen V: Mouse Small eye results from mutations in a paired-like homeobox-containing gene. Nature 1992, $355: 750$

63. Stoykova A, Fritsch R, Walther C, Gruss P: Forebrain patterning defects in Small eye mutant mice. Development 1996, 122:3453-3465.

64. Warren N, Caric D, Pratt T, Clausen JA, Asavaritikrai P, Mason JO, Hill RE, Price DJ: The transcription factor, Pax6, is required for cell proliferation and differentiation in the developing cerebral cortex. Cerebral Cortex 1999, 9:627-635.

65. Peng Y, Yang PH, Ng SS, Wong OG, Liu J, He ML, Kung HF, Lin MC: A critical role of Pax6 in alcohol-induced fetal microcephaly. Neurobiol Dis 2004, 16:370-376.

66. Aronne MP, Evrard SG, Mirochnic S, Brusco A: Prenatal ethanol exposure reduces the expression of the transcriptional factor Pax6 in the developing rat brain. Ann N Y Acad Sci 2008, 1139:478-498.

67. Powell EM, Campbell DB, Stanwood GD, Davis C, Noebels JL, Levitt P. Genetic disruption of cortical interneuron development causes regionand GABA cell type-specific deficits, epilepsy, and behavioral dysfunction. J Neurosci 2003, 23:622-631.

68. Hensch TK, Fagiolini M, Mataga N, Stryker MP, Baekkeskov S, Kash SF: Local GABA circuit control of experience-dependent plasticity in developing visual cortex. Science 1998, 282:1504-1508.

69. DuBois DW, Parrish AR, Trzeciakowski JP, Frye GD: Binge ethanol exposure delays development of GABAergic miniature postsynaptic currents in septal neurons. Brain Res Dev Brain Res 2004, 152:199-212.

70. Hsiao SH, Parrish AR, Nahm SS, Abbott LC, McCool BA, Frye GD: Effects of early postnatal ethanol intubation on GABAergic synaptic proteins. Brain Res Dev Brain Res 2002, 138:177-185.

71. Russo E, Citraro R, De Fazio S, Torcasio G, De Sarro G, Di Paola ED: Effects of ethanol on the development of genetically determined epilepsies in rats. Int J Dev Neurosci 2008, 26:739-744.

doi:10.1186/1423-0127-17-85

Cite this article as: Kim et al:: Prenatal exposure of ethanol induces increased glutamatergic neuronal differentiation of neural progenitor cells. Journal of Biomedical Science 2010 17:85.

\section{Submit your next manuscript to BioMed Central and take full advantage of:}

- Convenient online submission

- Thorough peer review

- No space constraints or color figure charges

- Immediate publication on acceptance

- Inclusion in PubMed, CAS, Scopus and Google Scholar

- Research which is freely available for redistribution 